\title{
Processos enzimáticos na biorremediação e fitorremediação de petróleo em sedimentos de manguezal: uma revisão
}

\author{
Enzymatic processes in oil bioremediation and phytoremediation in mangrove sediments: a review \\ Procesos enzimáticos en bioremediación y fitoremediación de aceite en sedimentos de manglar: una \\ revisión
}

Recebido: 27/08/2021 | Revisado: 02/09/2021 | Aceito: 07/09/2021 | Publicado: 08/09/2021

Eliseu Melo Carvalho Lacerda

ORCID: https://orcid.org/0000-0002-1565-2277 Universidade Federal da Bahia, Brasil E-mail: eliseu.carvalho@ufba.br

Willian Lázaro Alves Muniz de Santana ORCID: https://orcid.org/0000-0001-8536-9795 Universidade Federal da Bahia, Brasil E-mail: willian.lazaro@ufba.br

Milton Santos Cardoso Filho

ORCID: https://orcid.org/0000-0002-2277-6358 Universidade Federal da Bahia, Brasil

E-mail: cardososmilton@gmail.com

Naiara Cristina Pereira dos Santos ORCID: https://orcid.org/0000-0003-4156-5027 Universidade Federal da Bahia, Brasil E-mail: eng.naiara@gmail.com

Ícaro Thiago Andrade Moreira ORCID: https://orcid.org/0000-0002-3964-7368 Universidade Federal da Bahia, Brasil E-mail: icarotam@ufba.br

\begin{abstract}
Resumo
Diversos vazamentos de petróleo em mares e oceanos ocorreram nas últimas décadas, afetando principalmente estuários e manguezais. Acidentes ambientais envolvendo o petróleo, seus derivados e os resíduos gerados têm sido uma preocupação crescente, por conta dos hidrocarbonetos do petróleo ser considerados contaminantes orgânicos tóxicos e de difícil degradação. Os avanços biotecnológicos têm levado os pesquisadores a adotar a biorremediação e fitorremediação como alternativas potencialmente eficazes para solos e sedimentos contaminados e o uso enzimas têm sido adotado como uma estratégia além do uso de plantas e microrganismos na biorremediação. Este estudo consiste em uma revisão bibliográfica baseada em livros, artigos, teses, dissertações e sites, com o intuito de reunir e avaliar os processos enzimáticos na fitorremediação e fitorremediação em ambientes impactados por atividades do petróleo.
\end{abstract}

Palavras-chave: Manguezal; Sedimento; Petróleo; Remediação; Enzimas.

\begin{abstract}
Several oil spills in seas and oceans have occurred in recent decades, mainly affecting estuaries and mangroves. Environmental accidents involving petroleum, its derivatives and the waste generated have been a growing concern, as petroleum hydrocarbons are considered toxic organic contaminants that are difficult to degrade. Biotechnological advances have led researchers to adopt bioremediation and phytoremediation as potentially effective alternatives for contaminated soils and sediments, and the use of enzymes has been adopted as a strategy beyond the use of plants and microorganisms in bioremediation. This study consists of a literature review based on books, articles, theses, dissertations and websites, in order to gather and evaluate enzymatic processes in phytoremediation and phytoremediation in environments impacted by petroleum activities.
\end{abstract}

Keywords: Mangrove; Sediment; Petroleum; Remediation; Enzymes.

\section{Resumen}

En las últimas décadas se han producido varios vertidos de petróleo en mares y océanos, que han afectado principalmente a estuarios y manglares. Los accidentes ambientales relacionados con el petróleo, sus derivados y los desechos generados han sido una preocupación creciente, ya que los hidrocarburos del petróleo se consideran contaminantes orgánicos tóxicos y de difícil degradación. Los avances biotecnológicos han llevado a los investigadores 
a adoptar la biorremediación y la fitorremediación como alternativas potencialmente efectivas para suelos y sedimentos contaminados, y el uso de enzimas se ha adoptado como una estrategia más allá del uso de plantas y microorganismos en la biorremediación. Este estudio consiste en una revisión de la literatura a partir de libros, artículos, tesis, disertaciones y sitios web, con el fin de recopilar y evaluar procesos enzimáticos en fitorremediación y fitorremediación en ambientes impactados por actividades petroleras.

Palabras clave: Mangle; Sedimento; Petróleo; Remediación; Enzimas.

\section{Introdução}

O petróleo é uma mistura complexa de hidrocarbonetos, constituída por compostos orgânicos, óleos e compostos inorgânicos associados, tendo como principal constituinte hidrogênio e carbono, além de outros elementos em menor proporção (Tiab \& Donaldson, 2016; Viswanathan, 2017). Por ser um contaminante tóxico, carcinogênico, mutagênico, de difícil remediação e persistência no meio ambiente, os hidrocarbonetos causam uma série de problemas para a saúde humana e para os ecossistemas ambientais (Speight \& El-Gendy, 2018; Ozdemir, et al., 2021). Desta forma, estes compostos têm sido recomendados como poluente prioritário pela USEPA - Agência de Proteção Ambiental dos Estados Unidos - e vêm sendo amplamente documentados em estudos (Williams, et al., 2013; Marchand, et al., 2017; Lelis, et al., 2017).

Existe uma grande preocupação nas etapas de exploração de petróleo, desde a prospecção e principalmente nas operações de transporte e armazenamento, pois consideráveis quantidades de óleo e dos seus derivados podem ser derramadas ao meio marinho (Biazon, et al., 2015; Duleba et al., 2018). As zonas costeiras são uma das primeiras a serem atingidas após um derramamento de petróleo no ecossistema marinho (Lu, et al., 2011; Duke, 2016). Sendo que, em países tropicais e subtropicais, as regiões litorâneas concentram uma grande extensão de manguezais, que são ecossistemas de grande importância ecológica (Ghizelini, et al., 2019). Os manguezais são ecossistemas costeiros situados em regiões tropicais e subtropicais e são caracterizados como ambientes ecótonos por representarem uma zona de transição entre o ambiente marinho e terrestre (Abdulsalam, et al., 2011; Lim, et al., 2016). Esse ecossistema desempenha um papel fundamental nos processos ecológicos e são uma parte importante das economias das populações costeiras que dependem desse bioma, onde a pesca é uma fonte vital de alimento e renda (Syakti, et al., 2013).

Existem técnicas de remediação empregadas no tratamento de solos e sedimentos contaminados por petróleo e seus derivados, que podem ser in situ, como: air sparging, biosparging, bioventing, barreira reativa, biorremediação e fitorremediação (Andrade, et al., 2010; Mang Lu, et al., 2010). Assim como técnicas ex situ, tais como: oxidação química, dessorção térmica, biopilha e incineração (Dott, et al., 1995; Marimuthu, et al., 2017). A preferência nos últimos anos tem sido por métodos in situ, que forneçam menores riscos ao ambiente e que sejam economicamente viáveis. Neste contexto a biotecnologia oferece a biorremediação e a fitorremediação como alternativas que mais se enquadram às exigências (Silva et al., 2015; Moreira et al., 2015; Wu, et al., 2016, McIntosh, et al., 2017; Oliveira et al., 2020; Verâne et al., 2020).

A biorremediação é uma técnica que se baseia em mecanismos biológicos para biodegradar, desintoxicar ou biotransformar o contaminante, a utilização de um organismo vivo e natural para intensificar o processo de atenuação natural (Abdulsalam, et al., 2011; Lim, et al., 2016). Essas técnicas apresentam melhor viabilidade econômica, devida seu baixo custo, quando comparado a métodos tradicionais de correção de áreas degradadas, são mais sustentáveis e minimizam o contato com o contaminante (Haider, et al., 2021). O método de remediação biológica visa biodegradar, biotransformar e/ou remover contaminantes de uma matriz ambiental através da inserção de microrganismos ou plantas com capacidade de metabolizar o contaminante (Moreira, et al., 2016). A biorremediação pode ser aplicada em uma variedade de matrizes ambientais, a principais técnicas utilizadas são bioaumento (Ossai, et al., 2020; Tucci, et al., 2021).

A fitorremediação é uma técnica que utiliza plantas para degradar, extrair, acumular, volatilizar e estimular a biodegradação de contaminação na região da rizosfera da planta (Hussain, et al., 2018). É um conjunto de tecnologias em que a utilização da vegetação provoca um processo de depuração ambiental, através da fitodegradação e da fitoestabilização, fazendo 
com que ocorra a diminuição da concentração do contaminante (Steliga \& Kluk, 2020). Estes processos podem ocorrer da seguinte forma: a planta absorvendo o contaminante; a espécie associada à população microbiana auxilia na volatilização do contaminante; as raízes em associação com microrganismos degradam o contaminante na rizosfera; a planta secreta enzimas capazes de catalisar as reações químicas de degradação do contaminante em subprodutos não tóxicos (UNEP, 2012; Wang, et al., 2019; Hou, et al., 2021).

Uma das técnicas empregadas na remoção de petróleo em solos e sedimento é o uso de enzimas (Wang, et al., 2021). As enzimas são consideradas catalisadores biológicos que atuam controlando a velocidade das reações e sua principal importância no processo de biodegradação de petróleo é seu reaproveitamento, visto que elas não são consumidas no processo de aceleração das reações (Vigneswaran, Kandhavadivu \& Ananthasubramanian, 2014). As enzimas são moléculas orgânicas complexas produzidas por microrganismos, como bactérias, fungos e algas e organismos superiores como plantas, elas atuam como biocatalizadores dos contaminantes, permitindo que o processo de biodegradação ocorra (Kucharzyk, et al., 2018; Wang, et al., 2021).

O uso das enzimas, especialmente as purificadas, nos processos de biorremediação e fitorremediação de hidrocarbonetos é uma técnica em desenvolvimento e com grande potencial biotecnológico. Sendo assim, a presente pesquisa tem como objetivo apresentar por meio de uma revisão bibliográfica narrativa, os processos enzimáticos na remediação biológica de hidrocarbonetos em sedimentos de manguezais e suas possíveis aplicabilidades.

\section{Metodologia}

O presente estudo consiste em uma revisão narrativa baseada na metodologia descrita por Rother, (2007), na qual descreve que revisão narrativa e fundamenta-se em analisar criticamente, de forma qualitativa, a literatura disponível nos meios físicos e digitais. A autora também afirma que esse tipo de revisão executa um papel importante, pois, elas apresentam ao leitor um compilado de conceitos, definições e conhecimentos sobre um assunto específico.

Para esta revisão foram priorizados os artigos disponibilizados na íntegra em periódicos online, publicados entre 2010 a 2021, nos idiomas português e inglês. Utilizou-se as palavras chaves Bioremediation (Biorremediação), Remediação (Remediation) Enzyme (Enzima), Petroleum/Oil (Petróleo), Phytoremediation (Fitorremediação), Cinética (Kinetics), Sedimento (Sediment), Manguezal (Mangrove) e os operadores boleanos AND, OR e NOT para buscar os artigos em base de dados como Science Direct, Web of Science e Scielo. Os artigos selecionados foram lidos e avaliados rigorosamente de acordo com os critérios estabelecidos, sendo considerados aptos ou inaptos para compor a revisão proposta.

\section{Resultados e Discussão}

\subsection{Interações do petróleo no sedimento de manguezal}

A entrada dos hidrocarbonetos em ecossistemas marinhos, costeiros e estuarinos pode acontecer através de vias antropogênicas e biogênicas (Bianco, 2020). No processo de extração do petróleo, produção e distribuição de seus subprodutos o óleo é armazenado tanto em tanques de armazenamento tecnicamente adequados, como também, em locais inadequados para sua estocagem, dessa forma, o potencial para um derramamento de óleo é significativo e os efeitos do óleo derramado muitas vezes representam sérias ameaças ao meio ambiente (Premnath, et al., 2021).

Vazamento de tanques de armazenamento acima do solo ou subterrâneo, descarte impróprio de resíduos de petróleo, despejo de esgoto doméstico, industrial e derramamentos acidentais são as principais rotas de contaminação das matrizes solo, sedimento e água do manguezal, com produtos petrolíferos (Beiras, 2018). Quando o petróleo entra em contato com as matrizes presentes no manguezal ele se divide em três fases distintas, dissolvido, gasoso e líquido, parte desse hidrocarboneto dissolve no 
sedimento e nas águas, parte da substância permanece em forma líquida nos poros presentes do solo e parte volatiza (Maletić, et al., 2018).

O manguezal é localizado em terras baixas existentes nas zonas de entre marés em regiões costeiras, na maior parte das vezes, abrigado por rios, compreendendo um sistema estuarino diverso (Schmitt \& Duke, 2015). É um ecossistema costeiro de transição entre os biomas terrestre, marinho e estuarino, ou seja, é um biossistema que está altamente correlacionado a esses três biomas, demostrando sua alta complexidade e relevância para o equilíbrio da biota (Mukherjee, et al., 2014; Moreira, et al., 2016). Sua imensa importância para o equilíbrio nesses ambientes vem acompanhada da fragilidade desse sistema, que necessita do equilíbrio entre fatores como fauna, vegetação e maré, além da interação biogeoquímica entre organismos, água e sedimento (Spalding, Kainuma \& Collins, 2010; Ortega, et al., 2017).

Os sedimentos são resíduos fragmentados gerados a partir da ação do intemperismo físico e químico na rocha-mãe de uma área ou de uma formação geológica pré-existente, que podem ser transportados em suspensão ou como carga de fundo, durante a transportação através dos rios, vento e gelo, podendo ser de origem continental ou marinha (Aschenbroich, et al., 2015). Sedimentos estuarinos e costeiros podem ser considerados como uma mistura de material inorgânico e orgânico que chegou ao local de deposição como material particulado sólido ou foi incorporado aos sedimentos da solução através de diferentes maneiras (Wang, et al., 2018).

Os sedimentos são normalmente classificados de acordo com o tamanho do grão, cor, proporção relativa de substâncias orgânicas e inorgânicas, produtos químicos predominantes como silício e calcário e composição mineralógica (Ranjan, Routh \& Ramanathan, 2010). O componente orgânico de tais sedimentos é normalmente inferior a 10\% em peso (Zhong, et al., 2013). Sedimentos dos manguezais também são colonizados intensamente por microrganismos (bactérias, cianobactérias, fungos, algas; tamanho $-150 \mu \mathrm{m}$ ). Por meio de sua organização em biofilmes, os organismos criam seus próprios microhabitats, eles podem usar substratos e energia de forma eficaz para manter seus metabolismos em funcionamento em simbiose com o manguezal (Alfaro-espinoza \& Ullrich, 2015).

Os sedimentos de manguezal tendem a acumular compostos hidrofóbicos, devido à baixa energia hidrodinâmica, baixos níveis de oxigênio, granulometria fina e alto teor de carbono orgânico (figura 1) (Vaezzadeh, et al., 2015). Os compostos orgânicos do petróleo são substâncias apolares, logo são hidrofóbicos, ou seja, não possui afinidade com a água, diminuindo sua capacidade de solubilização (Maletić, et al., 2019). Assim, ao serem lançados no ambiente aquático, esses compostos tendem a se acumular em sedimentos e organismos, ampliando a persistência e o impacto ao ecossistema. E por consequência, devido a capacidade de biomagnificação deste poluente, pode ocorrer transferência de energia por acumulação nos níveis mais altos da cadeia trófica (Kumar, et al., 2021).

Derramamentos de petróleo e seus derivados em manguezais podem provocar efeitos agudos, que se manifestam em curto prazo, e crônicos, que irão provocar impactos observáveis após períodos de tempo mais longos (Parvanelli \& Loch, 2018; Duke, 2019). Antes de estabelecer os principais efeitos que o derramamento de óleo pode causar em manguezais, deve-se ter em mente que as respostas do ecossistema a este impacto irão depender de fatores químicos, físicos, oceanográficos e microbiológicos, tais como: a quantidade de óleo derramado, sua composição, a hidrodinâmica do local, disponibilidade de nutrientes, a irradiação solar, a temperatura, granulometria do sedimento, a composição da comunidade microbiana no meio, dentre outros fatores (Garcia \& La Rovere, 2011; Silva, 2019). Estes irão determinar a toxicidade e o tempo de permanência do óleo no ambiente, podendo explicar a variedade de respostas de diversos ecossistemas de manguezal após um derramamento de óleo (Verâne, et al. 2020). 
Figura 1: Derramamento de óleo em sedimento de manguezal.

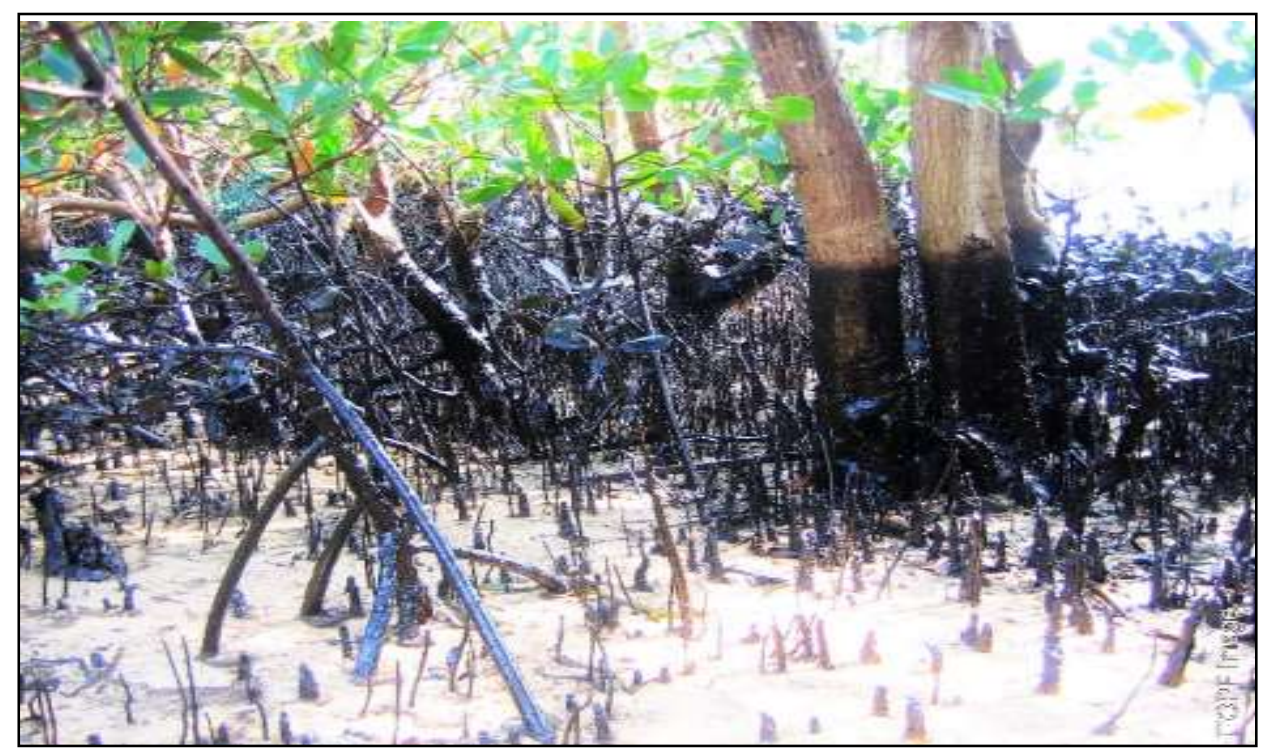

Fonte: ITOPF (2014).

A Figura 2 apresenta um fluxograma com alguns aspectos do impacto do óleo sobre os manguezais e o tempo médio para sua recuperação (Duke, 2016). Quando o óleo é liberado nas águas costeiras e estuarinas e levado para a costa, ele se deposita em superfícies sensíveis expostas durante as vazantes e fluxos diários regulares das marés (Michel \& Rutherford, 2014). Isso inclui os sedimentos que cobrem finamente as raízes finas e altamente sensíveis das árvores de mangue. Uma vez depositado, o óleo geralmente adere e raramente se move, tendo sido adsorvido às superfícies oleofílicas de plantas e animais (Kathiresan, et al., 2011; Saravanakumar, et al., 2016). Apenas em incidências onde os volumes de óleo são muito grandes ele reflui e continua a se espalhar de forma significativa com a subsequente descarga de maré (Saravanakumar, et al., 2016). Em cada caso, o óleo cobre as superfícies respiratórias das raízes, caules, mudas e sedimentos circundantes dos manguezais, bem como a fauna presente em tocas e cavidades de raízes (Kathiresan, et al., 2011).

A maioria dos componentes do óleo sofre intemperismo quando presentes em sedimentos de manguezal, mas a magnitude deste processo ainda é de difícil conhecimento (Verane, et al., 2020; Moreira, et al., 2011). As razões de nC17/Pristano e n-C18/Fitano vêm sendo usadas para avaliar a degradação (Moreira, et al., 2011). Porém esses isoprenóides são relativamente lábeis e, além disto, podem também provir da degradação da clorofila no meio ambiente, o que, muitas vezes, altera o resultado destas razões (Silva, 2016).

\subsection{Influência das enzimas na biorremediação}

A degradação microbiana tem sido amplamente estudada nos últimos anos na remoção de uma diversidade de xenobióticos, como o petróleo e suas diversas frações (Varjani \& Upasani, 2021), mas por se tratar de um processo relativamente lento e totalmente dependente da sobrevivência do microrganismo a viabilidade da sua aplicação muitas vezes é questionada. Em contrapartida, diversas pesquisas têm estudado a possibilidade da aplicação direta de enzimas microbianas nos processos de biorremediação de áreas contaminadas com hidrocarbonetos (Peixoto, Vermelho \& Rosado, 2011).

As enzimas podem ser produzidas por uma variedade de microrganismos na natureza, como bactérias, fungos, cianobactérias e algas, sendo capazes de degradar uma diversidade de contaminantes, são consideradas como macromoléculas orgânicas complexas que tem como principal função atuar como catalizadores orgânicos na degradação do contaminante (Kucharzyk, et al., 2018). Para ser utilizado na produção de enzimas, um microrganismo devem ser preferencialmente, seguro sob o ponto de vista biológico, possuindo status GRAS - generally recognized as safe, Food and Drug Administation (FDA), 
apresentar elevada capacidade de síntese e excreção da enzima, suportar condições ambientais adversas relacionadas com a pressão osmótica, a temperatura e a força iônica do meio, e ser tolerante à presença de substâncias tóxicas (Embrapa, 2015).

Figura 2: Fluxograma impacto do óleo sobre os manguezais e sua recuperação.

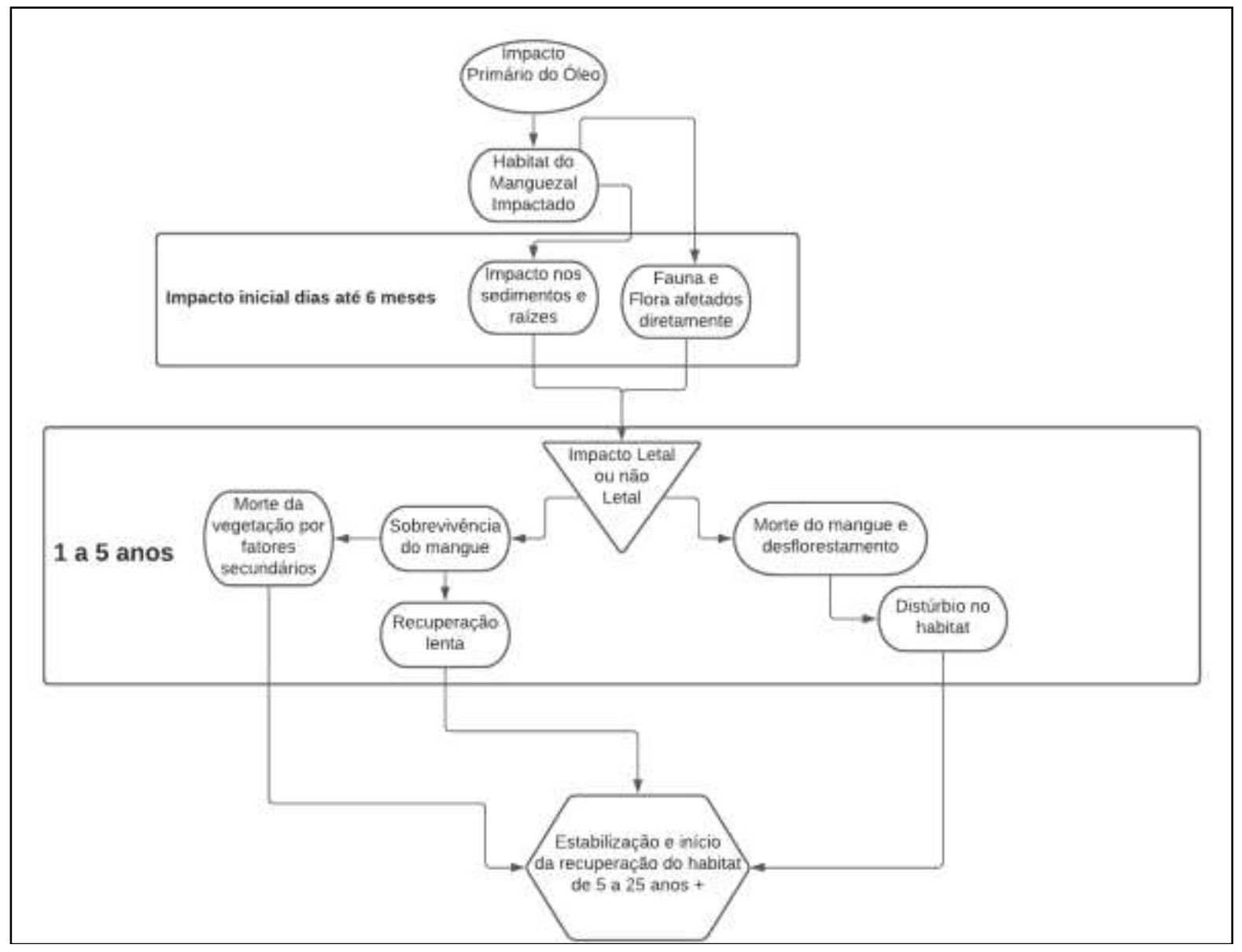

Fonte: Adaptado de Duke (2016).

Uma das principais vantagens do uso das enzimas é a não dependência de microrganismos específicos e de sua sobrevivência no processo de biorremediação, e sim da atividade catalítica específica que a enzima vai atuar, essa vantagem é reforçada principalmente em solos pobres de nutrientes e macronutrientes, onde a biodegradação do contaminante será possível apenas com o uso da enzima purificada e sem a necessidade da inserção de microrganismos, estimulantes ou plantas o para que o processo ocorra (Sharma, Dangi \& Shukla, 2018). Dindar, et al., (2015) demonstraram que a toxicidade do contaminante também influencia diretamente na atividade enzimática dos microrganismos presente no solo, reforçando novamente a ideia de que o uso apenas dos microrganismos pode diminuir consideravelmente as taxas de remoção do contaminante em relação a aplicação da enzima ou em associação aos microrganismos.

Dentre os principais grupos enzimáticos utilizados em um processo de biorremediação de hidrocarbonetos destacam-se as Oxigenases que tem como função clivar ligações químicas e auxiliar na transferência de elétrons de um substrato orgânico reduzido para outro composto químico, durante essas reações de oxidação-redução os contaminantes são oxidados em compostos menos nocivos e passíveis de mineralização (Mohsenzadeh, Chehregani Rad \& Akbari, 2012). Outro grupo amplamente utilizado são as monooxigenases, essas enzimas também são capazes de oxidar uma variedade de compostos orgânicos incluindo hidrocarbonetos (Singh \& Singh, 2017). 
As enzimas ligninolíticas extracelulares são um dos principais grupos de enzimas utilizadas em processos de biorremediação, Existem dois tipos de enzimas oxidativas extracelulares que são responsáveis pela degradação e desintoxicação da lignina e vários compostos xenobióticos, o primeiro Peroxidases como a Lignina peroxidase (LiP), Peroxidase de Manganês (MnP) e as peroxidades versáteis (VP) e a segunda as Oxidases com a Lacase ( $\mathrm{LaC})$, essas enzimas podem ser produzidas tanto por bactérias ou fungos (Acevedo, et al., 2010), e são amplamente estudas na remoção de hidrocarbonetos em solos e sedimentos e apresenta um abundante potencial biotecnológico em diversas áreas, nas indústrias, na produção de biocombustíveis, cosméticos e biorremediação.

Na biorremediação a LiPs, a MnPs e a VPs catalisam a oxidação de substratos usando peróxido de hidrogênio como oxidante. as LiPs são as únicas enzimas ligninolíticas que catalisam a oxidação moléculas aromáticas fenólicas e não fenólicas da lignina com ou sem mediadores, isso ocorre por meio de uma transferência de elétrons de longo alcance atribuída ao Tripofano (TRp171), localizado na superfície das LiP (Biko, Viljoen-Bloom \& Van Zyl, 2020).

O ciclo catalítico do LiPs é bem característico devido aos estados de oxirredução do Fe. O primeiro passo do ciclo é referente a oxidação do $\mathrm{Fe}$ da enzima nativa para $\mathrm{Fe}+$, pela ação do $\mathrm{H}^{2} \mathrm{O}^{2}$ que é um aceptor natural de elétrons que tem função de substrato na reação para a geração do composto oxidado, além da formação do radical catiônico da LiPs o álcool veratrílico com déficit de dois elétrons. Pela redução do composto oxidado a partir da transferência de um elétron ocorre a formação de outro composto em que o Fe está ainda como Fe+, mas não está como um radical livre, finalmente com a ação de um agente redutor um elétron é doado e o composto volta a forma de enzima nativa (Wong, 2009).

O ciclo catalítico das MnPs é similar ao da LiPs, começa com a oxidação por $\mathrm{H}^{2} \mathrm{O}^{2}$ ou peróxidos orgânicos que leva a enzima utilizada a um estado com déficit de dois elétrons na oxidação, dessa forma um composto inicial é formado. Dois processos consecutivos ocorrem para que a enzima seja reduzida até a forma nativa, nessa transição um composto intermediário é formado. O composto inicial pode ser convertido no composto intermediário de duas formas, tanto na presença de $\mathrm{Mn}^{2}+$ quanto na presença de outros doadores de elétrons com potencial redox apropriado, já a conversão do composto intermediário na enzima nativa com baixa massa molecular só ocorre na presença de $\mathrm{Mn}^{2}+$, podendo reagir com moléculas orgânicas especificadamente via hidrogênio (Hofrichter, 2002).

A lacase é uma das enzimas que são amplamente utilizada na remoção e biodegradação de hidrocarbonetos do petróleo, sendo o fungo da podridão branca o principal microrganismo associado a produção de lacase em processos biorremediação, a lacase é considerada uma enzima pouca exigente para a sua catálise do contaminante, pois exige apenas a presença de um substrato e oxigênio, podendo ser aplicadas tanto de forma livre ou imobilizada, sendo assim, por conta dessas características, considerada uma alternativa atrativa para aplicações biotecnológicas (Majeau, Brar \& Tyagi, 2010).

As enzimas ligninolíticas extracelulares podem ser aplicadas na remediação de hidrocarbonetos de diferentes maneiras, Niu, et al., (2013) propôs um modelo de remediação de HPAs e em um reator tipo Spider, que consiste no e encapsulamento da lacase em grânulos porosos dentro de fibras estruturais, a biodegradação ocorreu à medida que os HPAs fossem adsorvidos pelas fibras e consequentemente entrando em contato com os grânulos contendo a lacase tornando-o passível de ser degradado pela catálise enzimática. Alguns pesquisadores têm adotado diferentes técnicas sozinhas ou em associação entre elas, Dai, et al., (2020) utilizou um consócio lacase-bactéria imobilizado para remover óleo em uma região em uma região costeira contaminada com petróleo e teve remoção 66,5\% de óleo pesado após 100 dias e através da análise metagenômica foi demonstrando que o consórcio utilizado influenciou diretamente no aumento dos microrganismos degradadores de petróleo.

No estudo realizado por Álvarez-Barragán, et al., (2021) onde foi realizado ensaios laboratoriais com o intuito de biodegradar HPAS, com fungos da ordem Pleosporales, e dentro das espécies estudadas $85 \%$ tiveram uma taxa de remoção acima de 70\% de HPAs, nesse estudo foi identificado quatro enzimas que influenciaram diretamente na remoção dos HPAs a 
lignina peroxidase, manganês peroxidase, lacase e monooxigenases, demonstrando que espécies dessa mesma ordem possuem potencial de serem usadas na remoção de hidrocarbonetos.

Bulai, et al., (2021) produziu uma solução de enzimas através da fermentação de resíduos de frutas e vegetais em água misturada com açucares, resultado em uma solução enzimática bruta contendo diferentes enzimas extracelulares hidrolíticas, sendo as enzimas oxidorredutase e amilase, lipase e protease, as principais enzimas produzidas neste processo, elas pertencem à classe de enzimas hidrolases e como resultando obteve a redução de até $74 \%$ de degradação biocatalítica de óleo de motor em solo.

De acordo com o estudo de Kadri, et al., (2018) a enzima bruta extraída da bactéria marinha Alcanivorax borkumensis apresenta alta eficiência na remoção de hidrocarbonetos. O estudo confirma a alternativa de utilização de enzimas para a biorremediação de hidrocarbonetos. Foi observada uma alta atividade enzimática que ocasionou com mais de $80 \%$ de remoção de diferentes compostos como óleo de motor, hexadecano em diferentes concentrações em sedimento e solo contaminado, em cerca de 7 dias.

Libralato, et al., (2018) aponta uma série de problemáticas relacionadas a aplicação de biotecnologias na remediação in-situ de sedimentos contaminados, principalmente sedimentos de ecossistemas aquáticos e de difícil autodepuração, como o petróleo, que pode desencadear uma série de efeitos agudos e crônicos na região, e as informações disponíveis sobre os potenciais efeitos colaterais das atividades de remediação in-situ são escassas sendo necessário mais estudos que avaliem com atenção possíveis efeitos causados com a aplicação in-situ das técnicas de remediação atuais.

\subsection{Influência das enzimas na rizorremediação}

$\mathrm{O}$ uso de plantas superiores ou aquáticas na remoção de xenobióticos, principalmente hidrocarbonetos, no meio ambiente e é conhecida como fitorremediação, essa técnica tem sido estudada e aprimorada ao longo dos anos com a finalidade de biodegradar, imobilizar ou bioacumular uma variedade de xenobióticos (Cristaldi, et al., 2017). As plantas são povoadas por diversas comunidades microbianas, principalmente na região da rizosfera, uma área de intensa interação entre as raízes das plantas, microrganismos e solo, sendo importante para o sequestro de carbono impulsionado por microrganismos e ciclagem de nutrientes em ecossistemas terrestres (Deng \& Cao, 2017).

A rizorremediação é um dos principais mecanismos utilizado pelas plantas no processo de desintoxicação do ambiente, esse processo ocorre através da interação mútua entre a planta e a flora microbiana, os mecanismos de remoção do poluente do solo variam entre as espécies vegetais, porém, a maioria ocorre na região da rizosfera onde a interação simbiótica entre plantas e microrganismos acontece, pois nessa região as plantas fornecem um ambiente ideal para o crescimento dos microrganismos e ao mesmo tempo os microrganismos reduzem a toxicidade do solo e promovendo o crescimento e o metabolismo da planta (Ouvrard, Leglize \& Morel, 2014; Wei, et al., 2021), formando assim um ambiente simbiôntico mutualmente benéfico para ambos.

Apesar da fitorremediação ser apontada muitas vezes como uma técnica promissora na remoção de contaminantes orgânicos como o petróleo, as espécies vegetais não evoluíram para metabolizar contaminantes tóxicos como fonte de energia ou carbono, porém as plantas podem se adaptar ao estresse induzido estabelecendo sistemas de desintoxicação dentro de suas células onde os poluentes podem ser biotransformados em compostos menos nocivos, mais solúveis em águas ou até podem ser imobilizados (Feng, et al., 2017).

Um dos mecanismos utilizados no processo de adaptação é a parceria planta-microrganismos, esse mecanismo tem sido relatado como um fator importante no melhoramento da fitorremediação, por conta da capacidade das plantas e dos microrganismos interagirem entre si para tornarem o ambiente contaminado propenso para as reações metabólicas de ambos e consequentemente a recuperação, pois os microrganismos podem sintetizar vários compostos que ajudam as plantas a superar o 
estresse, fornecendo nutrientes essenciais para o crescimento e desenvolvimento da planta, melhorando o sistema de defesa da planta contra patógenos e estimulando a degradação de contaminantes (Ho, Hsieh \& Huang, 2013; Khan, et al., 2013).

A parceria planta-microrganismos são mutualmente benéfica além da relação metabólica dos microrganismos com o contaminante, as plantas também possuem capacidade de produzir uma série de exsudatos radiculares que tem como função participar das interações planta-microrganismos, estimulando os metabolismo nos microrganismos rizosféricos, tornando o ambiente menos tóxicos para os microrganismos, além de servir como uma fonte menos complexa de nutrientes e carbono para o microrganismos (Kotoky, Rajkumari \& Pandey, 2018).

A produção de enzimas pelos microrganismos com potencial biotecnológico é fortemente influenciada pelos mecanismos da rizorremediação, sendo a associação de plantas a microrganismos nos processos de biorremediação de petróleo um fator importante para o aumento das taxas de remoção dos contaminantes, Martin, et al., (2014) descreve que a presença dos exsudatos produzidos pelas plantas possuem influência direta na biorremediação, por conta da ação direta desses compostos sobre os contaminantes, onde podem agir diretamente na degradação inicial, podem contribuir com o aumento da fornecimentos de fósforo ou até mesmo aumenta a biodisponibilidade do contaminante para o microrganismos.

Liu, et al., (2014) apontou que a semeadura da E. Purpurea (L.) em solos contaminados com HPAs influenciou diretamente nas atividades desidrogenase, polifenol oxidase e urease, enquanto no experimento onde não houve a semeadura da planta não apresentaram diferenças significativas nas atividades enzimáticas, também foi observado que os exsudatos radiculares influenciam diretamente no aumento da densidade microbiana de degradadores de HPAs em solo, devido ao fato dos exsudatos estimulam significativamente os microrganismos que podem abrigar genes relacionadas a biodegradação de hidrocarbonetos (Liao, et al., 2021).

Em zonas interditais, como os manguezais, o uso da rizorremediação na recuperação de sedimentos contaminados com hidrocarbonetos tem sido descrito por alguns autores, como Verâne, et al., (2020), que utilizou a Rhizophora mangle como agente biorremediador de HPAs em sedimento de manguezal e obteve 60,76\% de remoção dos 16 HPAs de controle prioritário após 90 dias de experimento, Moreira, et al., (2013) conseguiu remover cerca de 87\% de HTPs em sedimento de manguezal após 90 dias utilizando a Avicennia schaueriana biorreatores, além que foi observado uma maior densidade microbiana nas região da rizosfera.

O uso de plantas na remoção de hidrocarbonetos é considera uma tecnologia em ascensão, pois tem sido constatado que diversas espécies possuem capacidade de degradar, imobilizar, solubilizar ou estimular a remoção de uma variedades de xenobióticos no meio ambiente, mas ainda necessita de uma série de estudos, principalmente pesquisas que façam o uso dessa técnica in-situ, para avaliar possível interferências ou interações com as variáveis da natureza, principalmente em regiões importantes como os estuários.

\subsection{Cinética das enzimas}

A cinética enzimática estuda a velocidade, atividade e seletividade dos produtos de formação, bem como os fatores que a influenciam, como pH, temperatura, concentrações de reagentes, enzimas, ativadores, inibidores, podendo também ser alvo de estudos para o controle, a otimização de processos e a projeção de reatores mais adequados (Schmal, 2013; Tischer, et al., 2019). As enzimas participam no mecanismo como um catalisador convencional, ou seja, incidem em torno da velocidade em que a transformação acontece no início da degradação (Razavi, Blagodatskaya \& Kuzyakov, 2016).

Sua eficiência como catalisador pode ser explicada através da concentração de sua atividade (U/ml), sendo determinado a partir da velocidade de reação, ou seja, a atividade enzimática corresponde à quantidade de enzima que catalisa para a formação de produto por unidade de tempo (Costa, 2016). Para reações catalisadas, a velocidade de reação pode ser acelerada para a ordem de milhões de vezes, por exemplo, a enzima orotidina monofosfato descarboxilase diminui o tempo 
de reação por ela catalisada de 78 milhões de anos para 25 milissegundos (Kadri, et al. 2018). Nos estudos dos processos enzimáticos, para remediação de sedimentos e solos contaminados por petróleo, a cinética tem importante destaque (Tan, et al. 2021). A cinética enzimática permite medir a velocidade que ocorre a biodegradação, além de avaliar os fatores que podem influenciar na taxa de degradação e consequentemente otimizar, estabelecendo critérios para o controle na aplicabilidade da biotecnologia (Loeppmann, Blagodatskaya, Pausch \& Kuzyakov, 2016).

No estudo de Kadri, et al., (2018), onde se utilizou a enzima bruta produzida por Alcanivorax borkumensis em diferentes tamanhos de inoculo para remoção de hidrocarbonetos no solo, foi apresentado os parâmetros cinéticos para avaliação da velocidade de remoção de HTPs. Como os dados de consumo de hidrocarbonetos foi possível constatar que a meia-vida estava por perto 5,12 dias. Podendo pressupor que levaria cerca de 10 dias para alcançar a biodegradação completa da fonte de carbono aplicando o inóculo testado e enzimas. De acordo com o estudo a biodegradação estimada no solo atingiu cerca de $64 \%$ de remoção de HTPs. A taxa de consumo global calculada (GCR) foi de cerca de 566,14 $\pm 42,1 \mathrm{mg} \mathrm{kg}-1$ d-1 para solo contaminado com $6170,7 \mathrm{mg}-1 \mathrm{~kg}-1$ de HTPs enquanto o consumo máximo foi de $363,4 \mathrm{mg}-1 \mathrm{~kg}-1$. A taxa de degradação usando enzimas de A. borkumensis foi muito importante para comparação com outras cepas que vem sendo estudadas para a situação em questão.

O estudo realizado por Tan, et al., (2021) concluiu que a qualidade do substrato é mais influente sobre a cinética enzimática quando em comparação com a diversidade de micróbios ativos e potencialmente ativos. Foi descoberto também que a velocidade das enzimas está significativamente relacionada à respiração microbiana, sendo que essa respiração é dependente da disponibilidade e qualidade do substrato também. Franco (2018) constatou que um biorreator, utilizado para avaliação da velocidade de consumo dos hidrocarbonetos totais do petróleo, foi eficiente na biodegradação. Entretanto a velocidade de consumo foi significativamente distinta nas unidades de simulação do tratamento contaminado, comprovando que apesar de terem sido realizados os mesmos procedimentos experimentais, cada unidade de simulação se comportou como um sistema à parte em relação à cinética.

\section{Considerações Finais}

As enzimas têm sido relatadas, em muitos estudos, pela sua alta aplicabilidade na remoção de xenobióticos, mas esses em sua maioria são ensaios laboratoriais que ignoram a influência da dinâmica biogeoquímica. Além da aplicação direta das enzimas existem outros fatores associados à sua produção e identificação. Considerando que uma série de microrganismos e enzimas ainda está sendo descobertos, principalmente microrganismos de regiões contaminadas, que já estarão adaptados ao contaminante e consequentemente produzirá uma resposta mais rápida.

Apesar de existirem diversas pesquisas que relatem o uso da rizorremediação na biodegradação de petróleo, ainda existe uma carência de pesquisas que avaliem uma relação entre os processos enzimáticos com os mecanismos da fitorremediação, principalmente pesquisas que envolva o uso de espécies endêmicas de manguezais. Além da carência de estudos relacionados à aplicação in-situ das enzimas, são poucos os estudos relacionados a aplicação em regiões estuarinas, que são regiões ricas em matéria orgânica e com alta salinidade. Existe uma série de lacunas relacionadas ao uso de enzimas na biorremediação, mas o seu uso já é considerado uma tecnologia emergente e de fácil aplicação e que tem demonstrado bons resultados na biodegradação de diversos de xenobióticos, principalmente os compostos do petróleo.

Sendo assim, para futuros ensaios e trabalhos científicos, sugere-se considerar e mensurar quão influente a dinâmica biogeoquímica afeta os sistemas associativos planta-microrganismos que estarão adaptados ao ambiente contaminado e a velocidade das enzimas secretadas. Recomendamos também avaliar os processos enzimáticos que ocorrem nos mecanismos de fitorremediação de espécies endêmicas de manguezais. 


\section{Agradecimentos}

Queremos agradecer ao Conselho Nacional de Desenvolvimento Científico e Tecnológico - CNPq, a Coordenação de Aperfeiçoamento de Pessoal de Nível Superior - CAPES e a FAPESB - Fundação de Apoio e Amparo à Pesquisa da Bahia pela concessão das bolsas de pós-graduação e iniciação científica e ao incentivo a pesquisa.

\section{Referências}

Acevedo, F. Pizzul, L., Castillo, M., González, M. E., Cea, M., Gianfreda, L., Diez, M. C. (2010). Degradation of polycyclic aromatic hydrocarbons by free and nanoclay-immobilized manganese peroxidase from Anthracophyllum discolor. Chemosphere, 80 (3), 271-278. 10.1016/j.chemosphere.2010.04.022.

Ajona, M., \& Vasanthi, P. (2021). Bioremediation of petroleum contaminated soils - A review. Materials Today: Proceedings, (45), 7117-7122. https://doi.org/10.1016/j.matpr.2021.01.949.

Alfaro-Espinoza, G \& Ullrich, M. S. (2015). Bacterial N2-fixation in mangrove ecosystems: insights from a diazotrophâ mangrove interaction. Frontiers in Microbiology, 6. 10.3389/fmicb.2015.00445.

Álvarez-Barragán, J., Cravo-Laureau, C., Wick, L. Y., \& Duran, R. (2021). Fungi in PAH-contaminated marine sediments: Cultivable diversity and tolerance capacity towards PAH. Marine Pollution Bulletin, 164. https://doi.org/10.1016/j.marpolbul.2021.112082.

AMAP. (1998). Chapter 10: Petroleum Hydrocarbons. AMAP Assessment Report: Arctic Pollution Issues, 661-701. http://www.osti.gov/energycitations/produ ct.bibl io.jsp?osti_id=5277590.

Aschenbroich, A., Marchand, C., Molnar, N, Deborde, J., Hubas, C., Rybarczyk, H., Meziane, T. (2015). Spatio-temporal variations in the composition of organic matter in surface sediments of a mangrove receiving shrimp farm effluents (New Caledonia). Science of The Total Environment, 512(513), 296307. 10.1016/j.scitotenv.2014.12.082.

Beiras, R., (2018). Chapter 7 -Hydrocarbons and Oil Spills. Sources, Fate and Effects of Pollutants in Coastal Ecosystems, 89-106. https://doi.org/10.1016/B978-0-12-813736-9.00007-6.

Bianco, R., Raceas, M., Papiro, S., Esposito, G. (2018). Chapter 7: Hydrocarbons and Oil. Spills, Sources, Fate and Effects of Pollutants in Coastal Ecosystems (ed.), 89-106. https://doi.org/10.1016/B978-0-12-813736-9.00007-6.

Biazon, C. L.; Barreto, G. O.; de Oliveira, E. C. (2015). The Impact of the Recovery in the Uncertainty Evaluation of the Oil and Grease by Extraction and Gravimetry in Produced Waters Derived From the Petroleum Extraction Process. Petroleum Science and Technology, 33(4), 487493. 10.1080/10916466.2014.987299.

Biko, O. , Viljoen-Bloom, Marinda, Van zyl, Willem H. (2020). Microbial lignin peroxidases: Applications, production challenges and future perspectives. Enzyme and Microbial Technology, (141), 109669. 0141-0229. 10.1016/j.enzmictec.2020.109669.

Bulai, I. S., Adamu, H., Umar, Yuguda, A., Sabo, A.(2021). Biocatalytic remediation of used motor oil-contaminated soil by fruit garbage enzymes. Journal of Environmental Chemical Engineering, 9(4), 105465. 10.1016/j.jece.2021.105465.

Costa, R. (2016). Degradação enzimática de clorofenol em microrreator. 84f. Dissertação (mestrado) - Universidade de São Paulo. Departamento de Engenharia Química. São Paulo.

Cristaldi, A., Conti, G. O., Jho, E. H., Zuccarello, P., Grasso, A., Copat, C., Ferrante, M. (2017). Phytoremediation of contaminated soils by heavy metals and PAHs. A brief review. Environmental Technology \& Innovation, (8), 309-326. 2352-1864. 10.1016/j.eti.2017.08.002.

Cui, L., Sun, H., Du, X., Feng, W., Wang, Y., Zhang, J., Jiang, J. (2021). Dynamics of labile soil organic carbon during the development of mangrove and salt marsh ecosystems. Ecological Indicators, 129, 107875. https://doi.org/10.1016/j.ecolind.2021.107875.

Cunningham, S. D., \& Ow, D. W. (1996). Promises and prospects of phytoremediation. Plant Physiology, 110(3), 715-719. https://doi.org/10.1104/pp.110.3.715.

Dai, X., LV, J., Yan, G., Chen, C., Guo, S., Fu, Pengcheng. (2020). Bioremediation of intertidal zones polluted by heavy oil spilling using immobilized laccasebacteria consortium. Bioresource Technology, (309), 123305. 0960-8524. 10.1016/j.biortech.2020.123305.

Dashtban, M., Schraft, H., Syed, T. A., \& Qin, W. (2010). Fungal biodegradation and enzymatic modification of lignin. International Journal of Biochemistry and Molecular Biology, 1(1), 36-50.

Deng, Z \& Cao, L. (2017). Fungal endophytes and their interactions with plants in phytoremediation: A review. Chemosphere, [S. 1.], (168), 1100-1106. 10.1016/J.chemosphere.2016.10.097.

Dindar, E., Topaç Şağban, F. O. \& Başkaya, H. S. (2015). Variations of soil enzyme activities in petroleum-hydrocarbon contaminated soil. International Biodeterioration and Biodegradation, ( 105), 268-275, 2015. 10.1016/j.ibiod.2015.09.011.

Duan, D., Lei, P., Lan, W., Li, T., Zhang, H., Zhong, H., \& Pan, K. (2020). Litterfall-derived organic matter enhances mercury methylation in mangrove sediments of South China. Science of the Total Environment, 765, 142763. https://doi.org/10.1016/j.scitotenv.2020.142763.

Duke, N. C. (2016). Oil spill impacts on mangroves: recommendations for operational planning and action based on a global review. Marine Pollution Bulletin, (109), 700-715. 10.1016/j.marpolbul.2016.06.082. 
Duleba, W., Teodoro, A. C., Debenay, J., Alves M., Maria V., Gubitoso, S., Pregnolato, L. A., Lerena, L. M., Prada, S. M., Bevilacqua, J. E., Dias, J. M. (2018). Environmental impact of the largest petroleum terminal in SE Brazil: A multiproxy analysis based on sediment geochemistry and living benthic foraminifera. PLOS ONE, 13(2), e0191446-. 10.1371/journal.pone.0191446.

Dunn R. J. K., Welsh D. T., Teasdale, P. R., Lee S. Y., Lemckert C. J., Meziane T.(2008). Investigating the distribution and sources of organic matter in surface sediment of Coombabah Lake (Australia) using elemental, isotopic and fatty acid biomarkers. Cont. Shelf Res., (28), 2535-2549. https://doi.org/10.1016/j.csr.2008.04.009.

Dzionek, A., Wojcieszyńska, D., \& Guzik, U. (2016). Natural carriers in bioremediation: A review. Electronic Journal of Biotechnology, (23), 28-36. https://doi.org/10.1016/j.ejbt.2016.07.003.

Feng, N. X., Yu, J., Zhao, H. M., Cheng, Y. T., Mo, C. H., Cai, Q. Y., Li, Y. W., Li, H., Wong, M. H. (2017). Efficient phytoremediation of organic contaminants in soils using plant-endophyte partnerships. Science of The Total Environment, 583, 52-368, 2017. 10.1016/j.scitotenv.2017.01.075.

Franco, E. (2018). Modelagem cinética microbiana aplicada na degradação do petróleo de campos presente no sedimento de manguezal. 88f. Dissertação (mestrado) - Universidade Federal da Bahia. Programa de Pós-graduação em Petróleo e Meio Ambiente. Salvador, Bahia.

Freitas, T. O. P., Pedreira, R. M. A., \& Hatje, V. (2021). Distribution and fractionation of rare earth elements in sediments and mangrove soil profiles across an estuarine gradient. Chemosphere, 264. https://doi.org/10.1016/j.chemosphere.2020.128431.

Garcia, K.C., La Rovere, E.L. (2011). Petróleo: acidentes ambientais e riscos à biodiversidade. Interciência, (232 p).

Haider, F. U., Ejaz, M., Cheema, S. A., Khan, M. I., Zhao, B., Liqun, C., Salim, M. A., Naveed, M., Khan, N., Núñez-Delgado, A., \& Mustafa, A. (2021). Phytotoxicity of petroleum hydrocarbons: Sources, impacts and remediation strategies. Environmental Research, 197. https://doi.org/10.1016/j.envres.2021.111031.

Harms, H., Schlosser, D., \& Wick, L. Y. (2011). Untapped potential: Exploiting fungi in bioremediation of hazardous chemicals. Nature Reviews Microbiology, 9(3), 177-192. https://doi.org/10.1038/nrmicro2519.

Ho, Y. N., Hsieh, J. L. \& Huang, C. C. (2013). Construction of a plant-microbe phytoremediation system: Combination of vetiver grass with a functional endophytic bacterium, Achromobacter xylosoxidans F3B, for aromatic pollutants removal. Bioresource Technology, (145), 43-47. 10.1016/j.biortech.2013.02.051.

HofrichteR, M. (2012). Review: lignin conversion by manganese peroxidase (MnP). Enzyme and Microbial Technology, 30 (4), 454-466. 10.1016/S0141$0229(01) 00528-2$.

Hou, J., Wang, Q., Liu, W., Zhong, D., Ge, Y., Christie, P., \& Luo, Y. (2021). Soil microbial community and association network shift induced by several tall fescue cultivars during the phytoremediation of a petroleum hydrocarbon-contaminated soil. Science of The Total Environment, (792), 148411. https://doi.org/10.1016/j.scitotenv.2021.148411.

Hussain, F., Hussain, I., Khan, A. H. A., Muhammad, Y. S., Iqbal, M., Soja, G., Reichenauer, T. G., Zeshan, \& Yousaf, S. (2018). Combined application of biochar, compost, and bacterial consortia with Italian ryegrass enhanced phytoremediation of petroleum hydrocarbon contaminated soil. Environmental and Experimental Botany, (153), 80-88. https://doi.org/10.1016/j.envexpbot.2018.05.012.

ITOPF. (2014). Oiled Mangrove, https://www.itopf.org/knowledge-resources/library/image-library/oiled-mangrove/>.

Kadri, T., Magdouli, S., Rouissi, T., \& Brar, S. K. (2018). Ex-situ biodegradation of petroleum hydrocarbons using Alcanivorax borkumensis enzymes. Biochemical Engineering Journal, (132), 279-287. https://doi.org/10.1016/j.bej.2018.01.014.

Kathiresan, K., Saravanakumar, K., Anburaj, R., Gomathi, V., Abirami, G., Sahu, Sk, \& Anandhan, S. (2011). Atividade de enzimas microbianas em folhas em decomposição de manguezais. International Journal of Advaced Biotechnology and Research, 2 (3), 382-389.

Khan, S., Afzal, M., Iqbal, S. \& Khan, Q. M. (2013). Plant-bacteria partnerships for the remediation of hydrocarbon contaminated soils. Chemosphere, 90 ( 4), 1317-1332. 10.1016/j.chemosphere.2012.09.045.

Kotoky, R., Rajkumari, J. \& Pandey, P. (2018). The rhizosphere microbiome: Significance in rhizoremediation of polyaromatic hydrocarbon contaminated soil. Journal of Environmental Management, (217), 858-870. 10.1016/j.jenvman.2018.04.022.

Kucharzyk, K. H., Benotti, M., Darlington, R. \& Lalgudi, R. (2018). Enhanced biodegradation of sediment-bound heavily weathered crude oil with ligninolytic enzymes encapsulated in calcium-alginate beads. Journal of Hazardous Materials, (357), 498-505, 2018. 10.1016/j.jhazmat.2018.06.036.

Kumar, A., Yadav, N., Mondal, R., Kour, D., Subrahmanyam, G., Shabnam, A., Khan, S., Kumar, K., Sharma, G., Pinto, M., Fagodiya, K., Guptard., Hota, S., Malyan, S. Myco-remediation: A mechanistic understanding of contaminants alleviation from natural environment and future prospect. Chemosphere, (284), 131325. https://doi.org/10.1016/j.chemosphere.2021.131325.

Liao, Q., Liu, H., Lu, C., Liu, J., Waigi, M. G., Ling, W. (2020). Root exudates enhance the PAH degradation and degrading gene abundance in soils. Science of The Total Environment, (764), 144436, 2021. 10.1016/j.scitotenv.2020.144436.

Libralato, G., Minetto, D., Lofrano, G., Guida, M., Carotenuto, M., Aliberti, F., Conte, B.; Notarnicola, M. (2018). Toxicity assessment within the application of in situ contaminated sediment remediation technologies: A review. Science of The Total Environment, (621), 85-94, 2018. 10.1016/j.scitotenv.2017.11.229.

Lim, M. W., Lau, E. Von, \& Poh, P. E. (2016). A comprehensive guide of remediation technologies for oil contaminated soil — Present works and future directions. Marine Pollution Bulletin, 109(1), 14-45. https://doi.org/10.1016/j.marpolbul.2016.04.023.

Lima, V. H. R., Fia, R., Sousa, L. S., Silva, R. A. \& Carvalho, M. V. (2019). Avaliação do capim-vetiver e capim-marandu na remediação de solo contaminado com óleo. A contaminação por poluentes orgânicos perigosos, os derramam. Sustentare. 3(1), 122-42. http://dx.doi.org/10.5892/st.v3i1.5712. 
Liu, R., Zhao, L., Jin, C., Xiao, N., Jadeja, R. N., Sun, T. (2014). Enzyme responses to phytoremediation of PAH-contaminated soil using echinacea purpurea (L.). Water, Air, and Soil Pollution, 225(12), 1-11. 10.1007/s11270-014-2230-4.

Loeppmann, S., Blagodatskaya, E., Pausch, J. \& Kuzyakov, Y. (2016). Substrate quality affects kinetics and catalytic efficiency of exo-enzymes in rhizosphere and detritusphere. Soil Biology and Biochemistry, (92), 111-118. 10.1016/j.soilbio.2015.09.020.

Madumini Senanayake, N. D., Ratnayake, A. S., Premila Wijesinghe, U. M., \& Ratnayake, N. P. (2021). Geochemistry and sedimentology of tropical mangrove sediments along the southwest coast of Sri Lanka: Fingerprints for development history of wetlands. Regional Studies in Marine Science, 46, 101884. https://doi.org/10.1016/j.rsma.2021.101884.

Majeau, J. A., Brar, S. K. \&Tyagi, R. D. (2009). Laccases for removal of recalcitrant and emerging pollutants. Bioresource Technology, 101( 7), 2331-2350, 2010. ISSN: 09608524. 10.1016/j.biortech.2009.10.087.

Maletić, S., Beljin,J., Rončević, S., Grgić, M., Dalmacija, B. (2018). State of the art and future challenges for polycyclic aromatic hydrocarbons is sediments: sources, fate, bioavailability and remediation techniques. Journal of Hazardous Materials, (365), 467-482.

Martin, B. C., George, S. J., Price, C. A., Ryan, M. H., Tibbett, M. (2014). The role of root exuded low molecular weight org anic anions in facilitating petroleum hydrocarbon degradation: Current knowledge and future directions. Science of The Total Environment, (472), 642-653. 10.1016/j.scitotenv.2013.11.050.

McIntosh, P., Schulthess, C. P., Kuzovkina, Y. A. \& Guillard, K. (2017). Bio- and Phytoremediation of Total Petroleum Hydrocarbons (TPH) Under Various Conditions. International Journal of Phytoremediation, 00-00. 10.1080/15226514.2017.1284753.

Michel J. \& Rutherford N. (2014). Impactos, taxas de recuperação e opções de tratamento para óleo derramado em pântanos Mar. Pollut. Touro. (82), 19 de - 25. 10.1016/j.marpolbul.2014.03.030.

Miri, S., Perez, J. A. E., Brar, S. K., Rouissi, T., \& Martel, R. (2021). Sustainable production and co-immobilization of cold-active enzymes from Pseudomonas sp. for BTEX biodegradation. Environmental Pollution, 117678. https://doi.org/10.1016/j.envpol.2021.117678.

Mohsenzadeh, F., Chehregani Rad, A., Akbari, M. (2012). Evaluation of oil removal efficiency and enzymatic activity in some fungal strains for bioremediation of petroleum-polluted soils. Iranian Journal of Environmental Health Science and Engineering, 9 (26), 26, 2012. 10.1186/1735-2746-9-26.

Moreira, I. T. A., Oliveira, O. M. C., Silva, C. S., Rios, M. C., Queiroz, A. F. S., Assunção, R. V. \& Carvalho, A. P. N. (2015). Chemometrics applied in laboratory study on formation of oil-spm aggregates (OSA) - a contribution to ecological evaluation. Microchemical Journal, 118, $198-202$.

Moreira, I. T. A., Oliveira, O. M. C., Triguis, J. A., Queiroz, A. F. S., Ferreira, S. L. C., Martins, C. M. S., Silva, A. C. M., Falcão, B. A. (2013). Phytoremediation in mangrove sediments impacted by persistent total petroleum hydrocarbons (TPH's) using Avicennia schaueriana. Marine Pollution Bulletin, 67( 1-2), 130136. 10.1016/j.marpolbul.2012.11.024.

Moreira, I., Oliveira, O. M., Triguis, J, Santos, A., Queiroz, A., Martins, C., Silva, C., Jesus, R. (2011). Phytoremediation Using Rizophora mangle L. in Mangrove Sediments Contaminated by Persistent Total Petroleum Hydrocarbons (TPH's). Microchem, (4), 376-382.

Moreira, I., Oliveira, O., Triguis, J., Santos, A., Azwell, T., Queiroz, A., Nano, R., Souza, E., Anjos, J., Assunção, R., Guimarães, I. (2016). Strategies of Bioremediation for the Degradation of Petroleum Hydrocarbons in the Presence of Metals in Mangrove Simulated. Clean -Soil, Air, Wate, (44) 631-637.

Moreira, I.; Oliveira, O.; Triguis, J.; santos, A.; Queiroz, A.; Ferreira, S.; Martins, C.; Silva, A.; Falcão. (2013). Phytoremediation in mangrove sediments impacted by persistent total petroleum hydrocarbons (TPH's) using Avicennia schaueriana. Marine Pollution Bulletin, (67), 130-136.

Mukherjee, N., Sutherland, S., Khan, M., Berger, U., Schmitz, N., Dahdouh-Guebas, F. (2014). Using expert knowledge and modeling to define mangrove composition, functioning, and threats and estimate time frame for recovery. Ecology and Evolution, 4(11), 2247-2262. 10.1002/ece3.1085

Niu, J., Dai, Y., Guo, H., Xu, J., Shen, Z. (2013). Adsorption and transformation of PAHs from water by a laccase-loading spider-type reactor. Journal of Hazardous Materials, [S. 1.], (248-249)1, 254-260. 10.1016/j.jhazmat.2013.01.017.

Oliveira, O. M. C., Queiroz, A. F. S., Cerqueira, J. R., Soares, S. A R., Garcia, K. S., Filho, A. P., Rosa, M. L. S., Suzart, C. M., Pinheiro, L. L. \& Moreira, I. T. A. (2020) Environmental disaster in the northeast coast of Brazil: Forensic geochemistry in the identification of the source of the oily material. Marine Pollution Bulletin, 160, 111597.

Ortega, P., Vitorino, H., Moreira, R., Pinheiro, M., Almeida, A., Custódio, M., Zanotto, F. (2017). Physiological differences in the crab Ucides cordatus from two populations inhabiting mangroves with different levels of cadmium contamination. Environmental Toxicology, 2(36), 361-371. https://doi.org/10.1002/etc.3537.

Ossai, I. C., Ahmed, A., Hassan, A., \& Hamid, F. S. (2020). Remediation of soil and water contaminated with petroleum hydrocarbon: A review. Environmental Technology and Innovation, 17, 100526. https://doi.org/10.1016/j.eti.2019.100526.

Ouvrard, S., Leglize, P. \& Morel, J. L. (2012). PAH Phytoremediation: Rhizodegradation or Rhizoattenuation? International Journal of Phytoremediation, 16 (1), 46-61, 2014. 10.1080/15226514.2012.759527.

Parvanelli, D \& Loch, C. (2018). Mangrove spectra changes induced by oil spills monitored by image differencing of normalised indices: tools to assist delimitation of impacted. Remote Sensing Applications: society and Environment, (12), 78-88.

Peixoto, R. S., Vermelho, A. B. \& Rosado, A. S. (2011). Petroleum-degrading enzymes: Bioremediation and new prospects. Enzyme Research, Hindawi Limited, 2011. 10.4061/2011/475193.

Prashanthi, M., Sundaram, R., Jeyaseelan, A., \& Kaliannan, T. (2017). Environmental Science and Engineering] Bioremediation and Sustainable Technologies for Cleaner Environment. Bioremediation-A Ecosafe Approach for Dairy Effluent Treatment, 45-50. 10.1007/978-3-319-48439-6_4. 
Premnath, N., Mohanrasu, K., Rao, R., Dinesh, G., Prakash, G., Ananthi, V., Ponnuchamy, K., Muthusamy, G., Arun, A. (2021). A crucial review on polycyclic aromatic Hydrocarbons - Environmental occurrence and strategies for microbial degradation Chemosphere, (280), 130608. https://doi.org/10.1016/j.chemosphere.2021.130608.

Rahman, M. S., Donoghue, D. N. M., \& Bracken, L. J. (2021). Is soil organic carbon underestimated in the largest mangrove forest ecosystems? Evidence from the Bangladesh Sundarbans. Catena, (200), 105159. https://doi.org/10.1016/j.catena.2021.105159.

Ranjan, R., Routh, J., Ramanathan, A. (2020). Bulk organic matter characteristics in the Pichavaram mangrove - estuarine complex, south-eastern India. Applied Geochemistry, 25(8), 1176-1186. https://doi.org/10.1016/j.apgeochem.2010.05.003.

Razavi, B., Blagodatskaya, E. \& Kuzyakov, Y. (2016). Temperature selects for static soil enzyme systems to maintain high catalytic efficiency. Soil Biology and Biochemistry, (97), 15-22. https://doi.org/10.1016/j.soilbio.2016.02.018.

Sánchez, C. (2020). Fungal potential for the degradation of petroleum-based polymers: An overview of macro- and microplastics biodegradation. Biotechnology Advances, (40), 107501. https://doi.org/10.1016/j.biotechadv.2019.107501.

Santos H., Carmo F., Paes J.S, Rosado A., Peixoto R. (2011). Biorremediação de manguezais impactados por petróleo Água Ar Solo Poluição. (216), 329 - 350.

Saravanakumar, K., Anburaj, R., Gomathi, V., \& Kathiresan, K. (2016). Ecologia de micróbios do solo em uma floresta de mangue tropical na costa sudeste da Índia. Biocatalysis and Agricultural Biotechnology, (8), 73-85. 10.1016/j.bcab.2016.08.01 .

Schmall M. Cinética e Reatores: teoria e exercícios - 2a ed. Rio de Janeiro, Editora Synergia: COPPE/UFRJ: FAPERJ, 2013, 678 p.

Schmitt, K. \& Duke, N. (2015). Mangrove management, assessment and monitoring, Tropical Forestry Handbook, eds L. Pancel and M. Köhl (Berlin; Heidelberg: Springer-Verlag), 30 .

Sharma, B, Dangi, A. K. \& Shukla, P. (2017). Contemporary enzyme based technologies for bioremediation: A review. Journal of Environmental Management, Academic Press. 10.1016/j.jenvman.2017.12.075.

Silva, J. (2016). Eficiência do mangue vermelho (Rhizophora mangle) na fitorremediação de sedimentos de manguezal contaminados por petróleo. 99f. Monografia (graduação em oceonografia) - Universidade Federal da Bahia. Instituto de Geociências. Salvador, Bahia.

Silva, J. (2019). Fitorremediação de hidrocarbonetos policíclicos aromáticos por Rhizophora mangle em sedimento de manguezal contaminado por petróleo bruto. 46f. Dissertação (mestrado) - Universidade Federal da Bahia. Programa de Pós-graduação em Petróleo e Meio Ambiente. Salvador, Bahia.

Silva, M. M., Leao, D. J., Moreira, I. T. A., Oliveira, O. M. C., Queiroz, A. F. S. \& Ferreira, S. L. C. (2015). Speciation analysis of inorganic antimony in sediment samples from São Paulo Estuary, Bahia State, Brazil. Environmental Science and Pollution Research, $22,8386-8391$.

Singh, J. S. \& Singh, D. P. (2017) Methanotrophs: An emerging bioremediation tool with unique broad spectrum methane monooxygenase (MMO) enzyme. In: Agro-Environmental Sustainability. [s.1.] : Springer International Publishing. (2), 1-18. 10.1007/978-3-319-49727-3_1.

Singh, S., Melo, J. S., Eapen, S., \& D’Souza, S. F. (2008). Potential of vetiver (Vetiveria zizanoides L. Nash) for phytoremediation of phenol. Ecotoxicology and Environmental Safety, 71(3), 671-676. https://doi.org/10.1016/j.ecoenv.2007.10.023.

Spalding, M., Kainuma, M., Collins, L., 2010. World Atlas of Mangroves. Earthscan, London. https://doi.org/10.4324/9781849776608.

Steliga, T., \& Kluk, D. (2020). Application of Festuca arundinacea in phytoremediation of soils contaminated with Pb, Ni, Cd and petroleum hydrocarbons. Ecotoxicology and Environmental Safety, (194)110409. https://doi.org/10.1016/j.ecoenv.2020.110409.

Tan, X., Nie, Y., Ma, X., Guo, Z., Liu, Y., Tian, H., Megharaj, M., Shen, W., He, W. (2021). Soil chemical properties rather than the abundance of active and potentially active microorganisms control soil enzyme kinetics. Science of The Total Environment, (770) 144500. https://doi.org/10.1016/j.scitotenv.2020.144500.

Tischer, A., Sehl, L., Meyer, U.-N.N., Kleinebecker, T., Klaus, V., Hamer, U., 2019. Land-use intensity shapes kinetics of extracellular enzymes in rhizosphere soil of agricultural grassland plant species. Plant Soil 437, 215-239. https://doi.org/10.1007/s11104- 019-03970-w.

Tong, T., Li, R., Chai, M., Wang, Q., Yang, Y., \& Xie, S. (2021). Metagenomic analysis of microbial communities continuously exposed to Bisphenol A in mangrove rhizosphere and non-rhizosphere soils. Science of The Total Environment, (792), 148486. https://doi.org/10.1016/j.scitotenv.2021.148486.

Varjani, S.; Upasani, V. N. (2021) Bioaugmentation of Pseudomonas aeruginosa NCIM 5514 - A novel oily waste degrader for treatment of petroleum hydrocarbons. Bioresource Technology, (319), 124240. 10.1016/j.biortech.2020.124240.

Verâne, J., Santos, N., Silva, V., Almeida, M., Oliveira, O., Moreira, I. (2020). Phytoremediation of polycyclic aromatic hydrocarbons (PAHs) in mangrove sediments using Rhizophora mangle. Marine Pollution Bulletin, (160), 111687. https://doi.org/10.1016/j.marpolbul.2020.111687.

Volkman J.K, Johns R.B, Gillan F.T, Perry G.J, Bavor Jr H.J. (1980). Lípidos microbianos de um sedimento intertidal. Ácidos graxos e hidrocarbonetos Geochim. Cosmochim. Acta, (44), 1133 - 1143. 10.1016/0016-7037(80)90067-8.

Wang, B., Xie, H. L., Ren, H. Y., Li, X., Chen, L., \& Wu, B. C. (2019). Application of AHP, TOPSIS, and TFNs to plant selection for phytoremediation of petroleum-contaminated soils in shale gas and oil fields. Journal of Cleaner Production, (233), 13-22. https://doi.org/10.1016/j.jclepro.2019.05.301.

Wang, H., Gilbert, J. A., Zhu, Y., Yang, X. (2018). Salinity is a key factor driving the nitrogen cycling in the mangrove sediment. Science of The Total Environment, (631-632), 1342-1349. 10.1016/j.scitotenv.2018.03.102.

Wang, J., Li, K., He, Y., Liu, X., Wang, P., Xu, L., Yan, J., \& Yan, Y. (2021). Bi-enzyme directed self-assembled system toward biomimetic synthesis of fatty acid hydroperoxides like soybean. Composites Part B: Engineering, (222), 109091. https://doi.org/10.1016/j.compositesb.2021.109091. 
Research, Society and Development, v. 10, n. 11, e526101119944, 2021

(CC BY 4.0) | ISSN 2525-3409 | DOI: http://dx.doi.org/10.33448/rsd-v10i11.19944

Wei, Z., Van Le, Q., Peng, W., Yang, Y., Yang, H., Gu, H., Lam, S. S., Sonne, C.(2021). A review on phytoremediation of contaminants in air, water and soil. Journal of Hazardous Materials, (403), 123658, 2021. 10.1016/j.jhazmat.2020.123658.

Wolfgang D., Doris F., Martin S., Petra M. B., Peter K. (1995). Comparison of ex situ and in situ techniques for bioremediation of hydrocarbon-polluted soils. 35(1-3), 301-316. 10.1016/0964-8305(95)00040-c.

Wu, Manli; Li, Wei, Dick, Warren A., Ye, Xiqiong, Chen, Kaili, Kost, David, Chen, Liming (2017). Bioremediation of hydrocarbon degradation in a petroleumcontaminated soil and microbial population and activity determination. Chemosphere, (169), 124-130. 10.1016/j.chemosphere.2016.11.059.

Zhong H., Kraemer L. \& Evans D. (2013). Influence of contact time and sediment composition on the bioavailability of Cd in sediments. 173, 10.1016/j.envpol.2012.09.021. 